\title{
PENINGKATAN PRODUKTIVITAS DAN PEMASARAN KOPI KELOMPOK TANI BUMI MAKMUR, DESA TEMBORO, KABUPATEN WONOGIRI
}

\author{
Okid Parama Astirin ${ }^{1,2}$, Suryanto ${ }^{1,3}$, Rahning Utomowati ${ }^{1,4}$, Candra Purnawan ${ }^{1,2}$, Bambang Sigit \\ Amanto ${ }^{1.5}$ \\ ${ }^{1}$ Pusat Penelitian Lingkungan Hidup, Universitas Sebelas Maret, Surakarta \\ ${ }^{2}$ Fakultas MIPA, Universitas Sebelas Maret, Surakarta \\ ${ }^{3}$ Fakultas Ekonomi, Universitas Sebelas Maret, Surakarta \\ ${ }^{4}$ FKIP, Universitas Sebelas Maret, Surakarta \\ ${ }^{5}$ Fakultas Pertanian, Universitas Sebelas Maret, Surakarta \\ okidparama@gmail.com , suryanto feb@staff.uns.ac.id, naning.geo@gmail.com, \\ candra_pr@yahoo.com, amantobambang@yahoo.co.id
}

\begin{abstract}
Abstrak
Desa Temboro, Kecamatan Karang Tengah, Kabupaten Wonogiri merupakan daerah penghasil kopi dengan kualitas rasa yang khas. Kopi asal Desa Temboro disediakan dalam bentuk green bean dan cherry, kemudian diolah menjadi produk kopi khas. Survei rantai niaga kopi yang terjadi di Desa Temboro sebagian besar petani hanya memiliki pilihan untuk menjual hasil panennya kepada tengkulak dan selanjutnya dijual kepada pengepul besar.

Mitra UD Bumi Makmur tinggal di desa Temboro, beranggota 14 rumah tangga yang masing-masing memiliki kebun kopi. Kelompok tani melakukan pengupasan buah dan kulit ari kopi menjadi kopi gabah menggunakan peralatan tradisional. Dari sisi aspek penghasilan petani, rantai niaga seperti ini mengakibatkan tidak maksimalnya pendapatan yang dapat diterima oleh pihak petani. Buah kopi yang telah dipanen dikupas menjadi kopi gabah (kopi dengan kulit tanduk). Kopi gabah kemudian dikeringkan dan dikupas untuk menghasilkan biji kopi beras (green bean). Biji kopi selanjutnya disangrai dan digiling untuk menghasilkan kopi bubuk siap konsumsi. Tahun 2019, harga kopi gabah dijual dengan harga minimum Rp25.000,-, namun tahun 2020 di awal masa pandemi, panenan kopi penawaran harga turun berada pada angka Rp15.000,-. Proses pengolahan biji kopi dilakukan di Rumah Produksi UD Bumi Makmur, sedangkan pemasarannya dilakukan di kawasan wisata hutan pinus Kemantren Kecamatan Karang Tengah, Kabupaten Wonogiri.
\end{abstract}

Kata Kunci : Kopi, Huller, Sangrai, Desa-Temboro, Wonogiri

\section{PENDAHULUAN}

Kopi merupakan salah satu minuman yang sangat di gemari oleh masyarakat Indonesia karena rasa dan aromanya. Minuman ini di gemari oleh segala umur secara turun temurun (Haryanto 2012; Ranitaswari et al., 2018). Komponen yang terdapat pada kopi adalah kafein, kaffeol, trigonelin, asam amino, karbohidrat, asam alifatik, asam chlorogenat, lemak, mineral, komponen volatil, dan komponen karbonil. kafein yang terdapat dalam kopi merupakan stimulan dari sistem saraf pusat sehingga dapat meningkatkan kinerja otak (Panggabean, 2011). Kopi Desa Temboro, Kecamatan Karang Tengah, Kabupaten Wonogiri merupakan salah satu daerah penghasil kopi yang tertinggi sesudah Kecamatan Girimarto (Kabupaten Wonogiri dalam angka, 2020). Kopi dihasilkan dalam bentuk green bean 
dan cherry, kemudian diolah menjadi produk kopi (Sembiring et al., 2019). Menurut Purnamayani (2014) kebanyakan petani kopi tradisional hanya menghasilkan kopi dalam bentuk basah. Survei rantai niaga kopi yang terjadi di Desa Temboro sebagian besar petani hanya memiliki pilihan untuk menjual hasil panennya kepada tengkulak dan selanjutnya dijual kepada pengepul besar. Dari tangan pengepul besar kemudian kopi ini didistribusikan hingga ke konsumen akhir melalui beberapa alur. Aspek penghasilan petani, rantai niaga seperti ini mengakibatkan tidak maksimalnya pendapatan yang dapat diterima oleh petani. Dalam proses yang terjadi petani kopi di Desa Temboro, petani hanya berperan dalam sebagian kecil proses pengolahan sehingga pendapatan yang diterima juga tidak maksimal. Proses pengolahan mulai dari buah kopi hingga menjadi kopi siap konsumsi menurut Raharjo (2012), melalui beberapa tahapan yang memberikan nilai tambah pada produk. Buah kopi yang telah dipanen dikupas menjadi kopi gabah (kopi dengan kulit tanduk). Kopi gabah kemudian dikeringkan dan dikupas untuk menghasilkan biji kopi beras (green bean) (Najiyati dan Danarti, 2004; Hujair dan Nashori, 2018).

Kelompok Tani Mitra UD Bumi Makmur tinggal di desa Temboro, Kecamatan Karang Tengah, Kab.Wonogiri, yaitu mene tanah yang subur dan ketinggian 1900 mdpl, yang sangat mendukung perkebunan kopi. Citarasa kopi sangat dipengaruhi oleh varietas, agroekologi, waktu panen, metode pemetikan, metode pengolahan dan metode penyimpanan (Siswoputranto, 1993). Kelompok tani melakukan pengupasan buah dan kulit ari kopi menjadi kopi gabah menggunakan peralatan tradisional. Dari sisi aspek penghasilan petani, rantai niaga seperti ini mengakibatkan tidak maksimalnya pendapatan yang dapat diterima oleh pihak petani. Biji kopi selanjutnya disangrai dan digiling untuk menghasilkan kopi bubuk siap konsumsi dengan peralatan yang sangat sederhana.

Penurunan konsumsi kopi berdampak pada menurunnya penawaran harga beli kopi dari tengkulak kepada petani. Tahun 2019, harga kopi gabah dijual dengan harga minimum Rp25.000,-, namun tahun 2020 di awal masa pandemi, panenan kopi penawaran harga berada pada angka Rp15.000. Akses ke pasar yang lebih luas menjadi sebuah kebutuhan untuk dapat meningkatkan pendapatan petani.

Produk TTG (teknologi tepat guna) yang dihasilkan dan diberikan ke mitra adalah penyangrai kopi dan huller kopi. Berdasarkan situasi yang ada dapat disimpulkan persoalan prioritas yang disepakati untuk diselesaikan dalam pelaksanaan kegiatan ini adalah Aspek Peningkatan Kapasitas Teknologi (Proses Produksi) dilakukan dengan Aspek teknologi yang akan diterapkan adalah terkait dengan proses pasca panen yang baik. Selain menerapkan metode pasca panen, pengolahan kopi juga didorong untuk dapat dilanjutkan pada tahapan pengolahan lebih lanjut untuk meningkatkan nilai jual yang dapat diperoleh oleh petani.

Aspek Teknologi Pemasaran/Distribusi, terbatasnya pilihan kepada siapa produk olahan kopi yang dihasilkan petani mengakibatkan terbatasnya potensi pendapatan yang dapat diterima oleh petani. Pemasaran yang dilakukan adalah di kawasan Wisata Kemantren (yang belum lama di bentuk oleh masyarakat setempat), yang menempati kawasan pegunungan hutan pinus, disamping itu pemasaran produk juga menggunakan teknik pemasaran menggunakan medsos yang diharapkan akan meningkatkan pemasaran. Pemasaran yang dapat dilakukan sederhana sesuai dengan kemampuan dan permintaan dari masyarakat mitra. Pemasaran ini juga didukung dengan branding pembuatan kemasan yang menarik oleh mitra Kelompok Tani UD Bumi Makmur.

\section{METODE}

Perancangan alat melibatkan perencanaan disain kapasitas (spek) bersama mitra UD Bumi Makmur sehingga sesuai dengan kebutuhan. Pendampingan juga dilakukan mulai dari instalasi alat, praktek langsung serta pelatihan untuk perawatan alat. Produk yang akan dihasilkan dan diberikan ke mitra adalah mesin huller kopi dan sangrai kopi (roasting). Produk lain yang juga mendukung percepatan pemasaran adalah disain pemasaran secara online dengan menggunakan instagram dan facebook sehingga jangkauan pembacanya lebih mudah. Target akhir dari kegiatan pengabdian ini adalah terinstalnya Mesin huller dan sangrai kopi (roaster) di mitra sehingga kualitas dan kuantitas produk mitra akan peningkat. 
Pengadaan Alat Mekanis Pengolahan Kopi mesin huller dan roasting (sangrai). Pengolahan bijih kopi menjadi meningkat kecepatannya. Pemasaran produk melalui media internet. Tersedianya web site profil kelompok tani dan caffee sederhana yang terdapat di kawasan wisata Kemantrean desan Temboro. Kawasan wisata desa Temboro merupakan inisiasi karang taruna yang ingin bangkit dengan menggali berbagai potensi produksi kawasan daerah Desa Temboro. Terdapat kelompok tani yang membuat herbal dalam bentuk cair dan inatant, kelompok kuliner makanan khas desa temboro dan caffee sederhana yang dibentuk oleh mitra kegiatan PKM ini. Kegiatan diawali dengan melakukan identifikasi masalah dan potensi yang ada pada Kelompok Tani UD Bumi Makmur di dusun Joso, Desa Temboro, Kec. Karang Tengah, Kab. Wonogiri. Pada tahap awal observasi ditemukan 3 masalah seperti telah diuraikan pada bagian analisis situasi. Hasil dari identifikasi masalah tersebut ditindak lanjuti oleh tim PKM Pusat Penelitian Lingkungan Hidup-LPPM UNS dengan Peningkatan Produktivitas dan Pemasaran Kopi Pada Kelompok Tani Bumi Makmur, di Desa Temboro, Kecamatan Karang Tengah, Kabupaten Wonogiri.

\section{HASIL DAN PEMBAHASAN}

\section{Sosialisasi dan Koordinasi Program}

Pada tahap awal dilakukan koordinasi dan sosialisasi program peningkatan kualitas produk kopi kepada Masyarakat Desa Temboro, yaitu mempersiapkan detil teknis peralatan sesuai dengan kapasitas mitra dan kebutuhan untuk pengolahan kopi. Selanjutnya program dijalankan melalui tahapan kegiatan secara terpadu, dimulai dari proses pertemuan masyarakat sasaran baik dalam bentuk pertemuan langsung ataupun melalui media online, hingga mewujudkan atau membangun nilai kesepahaman dan kesepakatan dalam kerjasama. Dengan demikian akan terbangun komitmen untuk melakukan kegiatan peningkatan produktivitas, mutu dan rasa/aroma kopi khas Desa Temboro. Proses koordinasi dan penyampaian teknis pelaksanaan kegiatan PKM pengolahan kopi secara online karena kondisi sedang PPKM. Telah disepakati spesifikasi peralatan sesuai dengan kebutuhan mitra dan disesuaikan dengan penggunaan energi listrik yang sesuai untuk mitra.

\section{2.. Penyuluhan dan Pengolahan Biji Kopi}

Penyuluhan tentang pengolahan Kopi merupakan inti dari hasil kopi yang siap di konsumsi oleh konsumen. Pengenalan tahap awal ini bertujuan agar para petani pengolah Kopi lokal mampu meningkatkan nilai jual kopi hasil tanaman masyarakat menjadi lebih baik. Dari segi pemasaran diharapkan hasil kopi Desa Temboro, Karang Tengah mampu bersaing di luar wilayahnya sendiri dan atau bisa bersaing dengan kopi olahan dari desa-desa lain penghasil kopi di Kabupaten Wonogiri.

Pelatihan Pengolahan Kopi Tahap kegiatan ini merupakan tindak lanjut dari penyuluhan awal tentang pengolahan biji Kopi di awal, dimana perlu disosialisasikan lebih luas kepada petani kopi dan masyarakat pelaku usaha Kopi. Kegiatan pelatihan pengolahan Kopi ini menghadirkan masyarakat tersebut untuk langsung mencoba dan praktek melakukan pengolahan kopi melalui metode Roasting dan kemudian merubah biji menjadi bubuk kopi medium. Pelatihan pemasaran kopi dalam bentuk bubuk dan penjualan kopi di kawasan wisata Kemantren Desa Temboro.

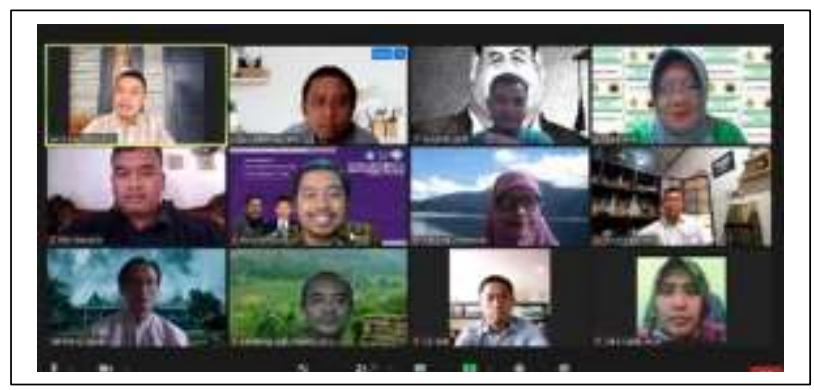

Gambar 1. Proses koordinasi dan penyampaian teknis pelaksanaan kegiatan PKM pengolahan kopi secara online karena kondisi sedang PPKM

Peningkatan kualitas kopi untuk menjadi komoditi unggulan Desa Temboro, Kecamatan Karang Tengah Wonogiri yang efektif adalah dengan mengadakan pendampingan dan dilakukan pelatihan dalam mengolah biji kopi yang dhasilkan menjadi produk kopi berkualitas mulai dari penyortiran, pengeringan, pengupasan, penyangraian, 
penggilingan/penghalus an biji kopi, pengemasan hingga penyimpanan kopi yang dihasilkan. Investasi peralatan pengolahan dalam bentuk mesin huller telah meningkatkan kualitas produk kopi, dengan menggunakan mesin, sebagaimana dapat dilihat di Gambar 2.

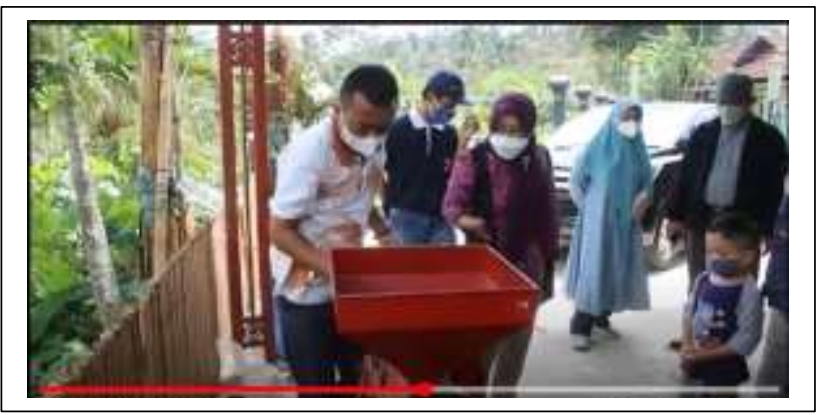

Gambar 2. Proses pengupasan kulit kopi dengan mesin huller yang diterapkan pada mitra

Melalui model teknologi industri rumah tangga dilakukan peningkatan produk kopi yang dihasilkan sehingga akan diperoleh hasil produk yang berkualitas dan berciri khas desa guna memaksimalkan potensi yang ada. Penggunaan mesin huller dapat meningkatkan kecepatan proses pengupasan kulit yang semula dengan alat tradisional dapat menghasilkan kopi kupas sebanyak $25 \mathrm{~kg}$ per jam, maka dengan menggunakan mesin huller kecepatan proses menjadi $250 \mathrm{~kg}$ per jam. Penelitian yang dilakukan oleh Aditya et al. (2016) terhadap karakteristik kopi mendapatkan hasil bahwasannya tidak ada perbedaan yang nyata terhadap variabel aroma kopi namun ada perbedaan yang nyata pada variabel rasa, sehingga faktor rasa kopi menjadi hal penting bagi konsumen. Proses sangrai yang terukur dari sisi aroma dan dengan suhu yang dapat dikendalikan akan menghasilkan aroma yang lebih baik. Investasi peralatan yang diberikan kepada mitra dalam bentuk mesin sangrai, sangat berpengaruh terhadap timbulnya aroma yang lebih kuat. Lama waktu pemanasan awal hingga $150-200^{\circ} \mathrm{C}$ adalah sekitar 15 menit, lalu proses penyangraian sebanyak per batch $0,5 \mathrm{~kg}$ per 15 menit (untuk hasil yang paling optimal menimbulkan aroma dan rasa yang terbaik), meskipun kapasitas maksimal mesin adalah $2 \mathrm{~kg}$ per batch. Mesin sangrai (roasting) yang diberikan kepada mitra dapat dilihat pada Gambar 3.

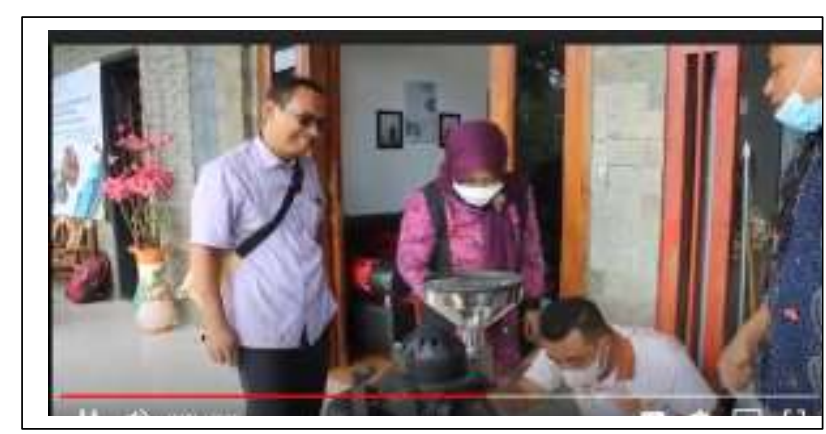

Gambar 3. Proses sangrai kopi (dengan mesin roasting) yang diterapkan pada mitra

Pola pelaksanaan secara tradisional yang ada dikembangkan menjadi pola pelaksanaan yang lebih maju dengan penggunaan mesin huller dan sangrai menggunakan mesin roasting telah berhasil meningkatkan kualitas kopi yang dihasilkan (dalam hal rasa dan aroma) dan meningkatkan kecepatan produksi. Perbedaan proses sebelum diterapkannya mesin huller dan mesin sangrai kopi (dengan mesin roasting) pada mitra dapat dilihat sebagaimana pada Gambar 4.

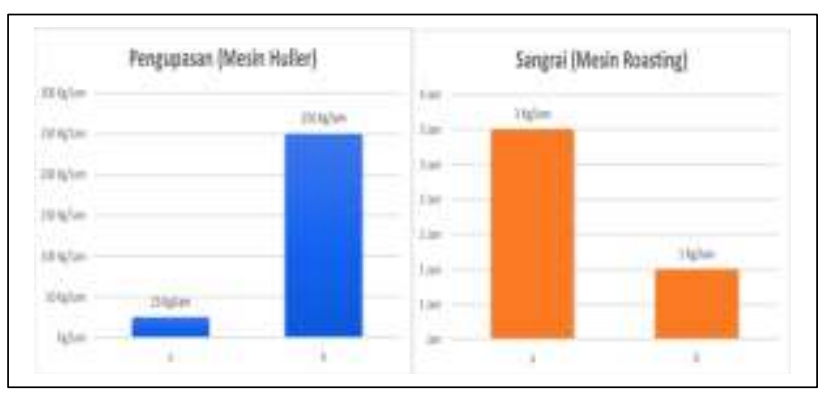

Gambar 4. Perbedaan proses sebelum diterapkannya mesin huller dan mesin sangrai kopi (dengan mesin roasting) pada mitra. Keterangan a. sebelum penerapan mesin; b. Sesudah penerapan mesin.

Kegiatan pendampingan mitra dalam kegiatan PKM dengan mengembangkan alat produksi dan pemasaran mampu meningkatkan kualitas dan kuantitas produk kopi secara signifikan dan menimbulkan rasa kopi yang lebih berkualitas dan disukai karena diolah dengan menggunakan peralatan yang standart. Diharapkan dengan adanya peningkatan kecepatan proses produksi maka 
pendapatan dari kelompok tani meningkat dan produk kopi dapat lebih dikenal sebagai penciri produk unggulan dan produk identitas dari Desa Temboro, kecamatan Karang Tengah Kabupaten Wonogiri.

\section{KESIMPULAN}

Pelaksanaan kegiatan pengabdian kepada masyarakat dengan tim dari PPLH-LPPM Universitas Sebelas Maret yang telah dilaksanakan di Desa Temboro Kecamatan Karang Tengah ini mendapatkan respon positif dari masyarakat, petani kopi, dan juga pemerintah Kabupaten Wonogiri. Kopi yang ada selama ini diolah dengan cara tradisional dan hasilnya kopi gosong sehingga tidak ada rasanya dan tidak berbau harum. Melalui pelaksanaan Program pengabdian kepada masyarakat skim PKM ini luaran program yang dihasilkan adalah peningkatan kapasitas dari petani kopi untuk dapat mengolah dan memasarkan secara langsung.

\section{UCAPAN TERIMAKASIH}

Ucapan terimakasih disampaikan kepada Universitas Sebelas Maret yang telah memberikan kontribusi dalam pelaksanaan kegiatan melalui pendanaan PKM pada tahun 2021.

\section{REFERENSI}

Aditya, W. I., Nocianitri, A. K., Yusasrini, A. L. N. (2016). Kajian Kandungan Kafein Kopi Bubuk, Nilai pH Dan Karakteristik Aroma Dan Rasa Seduhan Kopi Jantan (Pea Berry Coffee) Dan Betina (Flat Beans Coffee) Jenis Arabika Dan Robusta. Jurusan Ilmu dan Teknologi Pangan, Fakultas Teknologi Pertanian, Universitas Udayana.

Badan Pusat Statistik, Kabupaten Wonogiri (2020), Kabupaten Wonogiri dalam Angka 2020, Penerbit BPS Kab. Wonogiri, ISSN: 0215-6229, hal 225.
Haryanto, B. (2012). Prospek Tinggi Bertanam Kopi. Yogyakarta: Pustaka Baru Press.

Najiyati S. dan Danarti., (2004). Budidaya Tanaman Kopi dan Penanganan Pasca Panen. Penebar Swadaya. Jakarta.

Panggabean, E. (2011). Buku Pintar Kopi. Jakarta: PT. Argo Media Utama

Purnamayani, R. (2014). Mengenal Kopi Liberika Tungkal Komposit (Libtukom) Khas Jambi. Balai Pengkajian Teknologi Pertanian Jambi. http://jambi.litbang.pertanian.go.id/ind/index.ph p/berita/4-info-aktual/306 mengenal-kopiliberika-tungkal-komposit-libtukom-khas-jambi. Akses pada 12 Sept 2021.

Rahardjo, P. (2012). Panduan Budidaya dan Pengolahan Kopi Arabika dan Robusta, Penebar Swadaya. Jakarta.

Ranitaswari P.A, Mulyani S, Sadyasmara C.A.B, (2018). Analisis Kepuasan Konsumen Terhadap Kualitas Produk Kopi Dan Kualitas Pelayanan Menggunakan Metode Importance Perfomance Analysis (Studi Kasus Di Geo Coffee) Jurnal Rekayasa dan Manajemen Agroindustri ISSN: 2503-488X, Vol. 6. No. 2. April 2018 (147-157)

Sanaky H.A.H dan Nashori F. (2018) Peningkatan Dan Pengembangan Produk Olahan Kopi Di Desa Brunosari, AJIE - Asian Journal of Innovation and Entrepreneurship (e-ISSN: 24770574 ; p-ISSN: 2477-3824) Vol. 03, Issue. 03, September 2018

Sembiring A.C, Sitanggang D., Purnasari N., Budiman I. (2019). Peningkatan Kesejahteraan Petani Kopi Melalui Pengolahan Pasca Panen Di Desa Lingga Kabupaten Karo. Jurnal Wahana Inovasi Volume 8 No.2 Juli-Des 2019 ISSN : 2089-8592

Siswoputranto, PS. (1993). Kopi Internasional dan Indonesia. Kanasius. Jakarta. 